\title{
Prevalence of Gastroesophageal Reflux Symptoms among People in a Village, Sherpur, Bangladesh
}

\author{
Hasan $\mathrm{MN}^{1^{*}}$, Rakib $\mathrm{KHB}^{2}$, Akbar $\mathrm{S}^{3}$, Asaduzzaman $\mathrm{M}^{4}$
}

${ }^{1}$ Dr. Mohammad Nadim Hasan, Assistant Professor, Department of Medicine, Sheikh Hasina Medical College, Jamalpur, Bangladesh

${ }^{2}$ Dr. Kabirul Hasan Bin Rakib, Junior Consultant, Department of Medicine, Dhaka Medical College, Dhaka, Bangladesh

${ }^{3}$ Dr. Shafiqullah Akbar, Assistant Professor, Department of Medicine, Sheikh Hasina Medical College, Jamalpur, Bangladesh

${ }^{4}$ Dr. Mohammad Asaduzzaman, Assistant Professor, Department of Pediatric, Sheikh Hasina Medical College, Jamalpur, Bangladesh

DOI: $10.36347 /$ sjams.2020.v08i12.036

| Received: 15.12.2020 | Accepted: 23.12.2020 | Published: 29.12.2020

*Corresponding author: Dr. Mohammad Nadim Hasan

Abstract

Original Research Article

Introduction: GERD is a common and chronic gastrointestinal disorder with a significant negative impact on health related quality of life. Heartburn and regurgitation, typical symptoms of GERD are considered to be reasonably specific for diagnosis. Several factors may predispose patient to pathological reflux including hiatus hernia, lower esophageal sphincter hypotension loss of esophageal peristaltic function, increase intra-abdorninat pressure due to chronic cough, BEP, obesity and pregnancy, gastric hyper Secretary state, delayed gastric empting and overeating, etc. Often multiple factors are present. Objective: This study was carried out to find out prevalence of GERD symptoms among people in a rural area of Bangladesh. Methodology: This study was descriptive, cross sectional observational study. The study was carried out from 8th, October, 2012 to $10^{\text {ln }}$, April, 2013 for a period of 6 months. 384 people were participant from Kamaria village of Sherpur district, Categorical variables were reported as percentage and Correlation was carried out Using the Chi-square test $\left(\mathrm{X}^{2}\right.$-test $)$ through determining the association of different variables by SPSS software version-22. Result: Our present study has shown that $18.75 \%$ people have GERD symptoms. It is more common among female $(22.44 \%)$ than male $(14.89 \%)(\mathrm{p}<0.05)$. Study population was 384 and male (188) female (196) number was almost equal. Among study population $51.82 \%$ people was in age group $18-38$ years, 33.85\% was age group 39-59years, and 14.32\%was age group>59years Among GERD patient 12 has mild symptoms, 22 has moderate symptoms and 38 has severe symptoms. Most GERD patients are of age group 39-58years (male-14, female-20) Average weight of GERD patient is $54.33 \mathrm{~kg}$ in case of male and $48.66 \mathrm{~kg}$ in case of female which is greater than normal people ( $\mathrm{p}<0001)$. GERD patient have BMI (male-20.44. female-24 13) which is greater than normal people (male-19.82, female-23.63). GERD patient consume Biri, Batle nut and Tobacco leaf more than normal people. Conclusion: On the basis of the results of the present study, integrated with the understanding from the available literature this study found that statistically significant positive correlation between previous study and present study In the prevalence of GERD.

Keywords: Gastro-esophageal, GERD, symptoms.

Copyright (C) 2020 The Author(s): This is an open-access article distributed under the terms of the Creative Commons Attribution 4.0 International License (CC BY-NC 4.0) which permits unrestricted use, distribution, and reproduction in any medium for non-commercial use provided the original author and source are credited.

\section{INTRODUCTION}

Gastro-esophageal reflux disease is a highly prevalent Gastrointestinal disorder and is one of the most common GI illnesses encountered in clinical practice. The prevalence of Gastro- esophageal reflux disease is believed to be less in Asian than in western countries. When symptoms of gastro-esophageal reflux disease are typical, and the patient responds to therapy no diagnostic tests are necessary to verify the diagnosis, rather the usual reasons prompting diagnostic testing are to avert misdiagnosis, to identify any complications. Our current understanding of the epidemiology of GERD is primarily based on population based crosssectional studies conducted in the affluent western region like USA and Europe. Population based data on GERD is scarce from developing countries in Asia including Bangladesh. This study has been designed so as to generate objective data regarding the prevalence of the disease in Bangladesh. The diagnosis of GERD will be made on the basis of symptoms only, without the use of invasive test. GERD is a common and chronic gastrointestinal disorder with a significant negative impact on health related quality of life [1]. Heartburn and regurgitation, typical symptoms of GERD are considered to be reasonably specific for diagnosis [2]. A validated symptoms score based on heartburn and regurgitation is a useful diagnostic tool to conduct epidemiological studies in GER0 [3], The following definition is used to identify the symptoms of GERD. 
(1) Heart burn is defined as a burning sensation or discomfort behind the breastbone in the chest. (2) Acid regurgitation is defined as a bitter test or sour testing fluid coming in to the mouth [3] Occasional episodes of gastro-esophageal reflux are common in health, Reflux is normally followed by esophageal peristaltic waves which efficiently clear the gullet, alkaline saliva neutralizes residual acid and symptoms do not occur. GERD develops when the esophageal mucosa is exposed to gastro-duodenal content for prolonged period of time and resulting in symptoms [4]. GERD can also produce symptoms or signs of tissue injury within the oropharynx, larynx and respiratory tract. Recent studies have suggested GERD causes a wide spectrum of non-esophageal conditions including asthma, non-obstructive dysphagia and non-cardiac chest pain [5]. Moreover it has been reported that acid suppression therapy resolves heartburn and epigastric pain in GERD patients $[6,7]$. A current definition of the disorder is a condition which develops when the reflux of stomach contents causes troublesome symptoms (at least two heart burn episodes per week) and / or complication [8]. Several extra-esophageal manifestations of the disease are well recognized including laryngitis and cough, With respect to the esophagus the spectrum of injury includes esophagitis, stricture, and the development of columnar mataplasia in place of normal squamous epithelium and Adenocarcinoma [9, 10]. Esophagitis occur when excessive reflux of acid and pepsin results in necrosis of surface layers of esophageal mucosa causing erosion and ulcers. Several factors may predispose patient to pathological reflux including hiatus hernia [11], lower esophageal sphincter hypotension, and loss of esophageal peristaltic function, increase intraabdominal pressure in obesity and pregnancy [12], gastric hypersecretory state, delayed gastric empting and overeating, often multiple factors are present [13]. GERD is a common condition and its prevalence varies in different parts of the world Several population based studies have reported its prevalence is more frequent In western than in eastern countries. In the United States, $44 \%$ of the adult population has reported experiencing heartburn at least once a month, 14\% have reported experiencing it weekly, and $7 \%$ have reported experiencing it daily [1]. A traditional belief is that GERD occurs less frequently in Asia than in western countries however there is an emerging suggestion that the prevalence of GERD might be on the rise in Asia [15]. Prevalence of GERD in an urban adult population from northern India is $16.2 \%$ which is similar to other industrialized countries [3].

\section{Materials and Methods}

A descriptive, cross sectional observational study was considered suitable for this study. The study was conducted in the Kamaria village under Sherpur district. The study was carried out over a period of 6 months from 8th, October, 2012 to $10^{\text {th }}$, April, 2013. Total 384 study populations were included in this study. Sampling was done by simple random method. There are about 1300 voter in Kamaria village, of them half are women. So every $3^{\text {rd }}$ person of the voter list was selected and was included in study if they fulfilled the criteria. Total 384 study populations were included in this study. Data were collected from the Adult people of Kamaria village of sherpur district who meet the inclusion criteria through a validated questionnaire. Sampling was done by simple random method. There are about 1300 voter in Kamana village. Of them half are women. So every $3^{\text {rd }}$ person of voter list was selected and included in study. Expert Assistance was taken from Gastroenterologist of the department of Gastroenterology of Mymensingh Medical College Hospital and two volunteers who assist me to collect information. Source of funding was Self.

\section{Inclusion Criteria}

- Age above 18 years.

- Those who have given informed consent to participate.

\section{Exclusion Criteria}

- Those who are pregnant.

- History of operation for GIT disease, gall bladder disease or pancreatic disease.

- Diagnosed cases of IHD and taking anti anginal drugs.

- Diagnosed cases of chest pain and throat pain due to other cause.

- Psychiatric illness. No invasive procedure was done in this study.

\section{RESULT}

The present study intended to find out the Prevalence of Gastro Esophageal reflux symptoms among rural people of Bangladesh by collecting data from the Kamaria village under Sherpur district. We have studied 384 populations. Age frequency among total population was 199 (51.82\%) from 18-38 years, $130(33.85 \%)$ from $39-59$ years and $55(14.32 \%)$ from 60 years of age and above (Table-1). Among the study population of 384 cases, it was seen that 188 (48.95\%) were male and196 (51.05\%) were female (Table-2). Among the study population of 384 cases 72 $(18.75 \%)$ person had symptoms score more than 4 , i.e. presence of GERD symptoms and $312(81.85 \%)$ cases has symptoms score less than 4 , i.e. absence of GERD symptoms (Table-3). Among them 28(38.88\%) person was male and $(61.12 \%)$ person was female (Table-4). Among all GERD patient 12 patient have symptoms score 4-8. 22 patient have symptoms score 914 and 38 patient have symptoms score 15-18. Among 72 GERD patient 35 patient are of age group 18-38. 27 patient are of age group 39-59 years, 10 patients are of age group 18-38. Average weight of male GERD patient was $54.33 \mathrm{~kg}$ which was than average weight $(52.66 \mathrm{~kg})$ of population without GERD (Table-7). 
Average weight of female GERD patient was $54.33 \mathrm{~kg}$ which was than average weight $(52.66 \mathrm{~kg})$ of population without GERD (Table-8). Bar chart-2 showing $13.88 \%$ GERD patient having history of taking tobacco leaf/battle nut/smoking, While only $10.25 \%$ general people having similar habit $4.16 \%$ GERD patient have no history of taking anu from of tobacco where $18.26 \%$ general people have no history any form of tobacco.

Table-1: Age distribution of the study population $(n=384)$

\begin{tabular}{|l|l|l|}
\hline Age & $\mathbf{n = 3 8 4}$ & $\mathbf{( \% )}$ \\
\hline $18-38$ & 199 & 51.82 \\
\hline 39.59 & 130 & 33.85 \\
\hline$>59$ & 55 & 14.32 \\
\hline Total & 384 & 100 \\
\hline
\end{tabular}

Table-2: Sex distribution of the study population $(n=384)$

\begin{tabular}{|l|l|l|}
\hline Sex & $\mathbf{n = 3 8 4}$ & $(\mathbf{\%})$ \\
\hline Male & 188 & 48.95 \\
\hline Female & 196 & 51.05 \\
\hline Total & 384 & 100 \\
\hline
\end{tabular}

Table-3: GERD Symptoms distribution of the study population $(n=384)$

\begin{tabular}{|l|l|l|}
\hline GERD symptoms. & $\mathbf{n = 3 8 4}$ & $\mathbf{( \% )}$ \\
\hline Present & 72 & 18.75 \\
\hline Absent & 312 & 81.25 \\
\hline Total & 384 & 100 \\
\hline
\end{tabular}

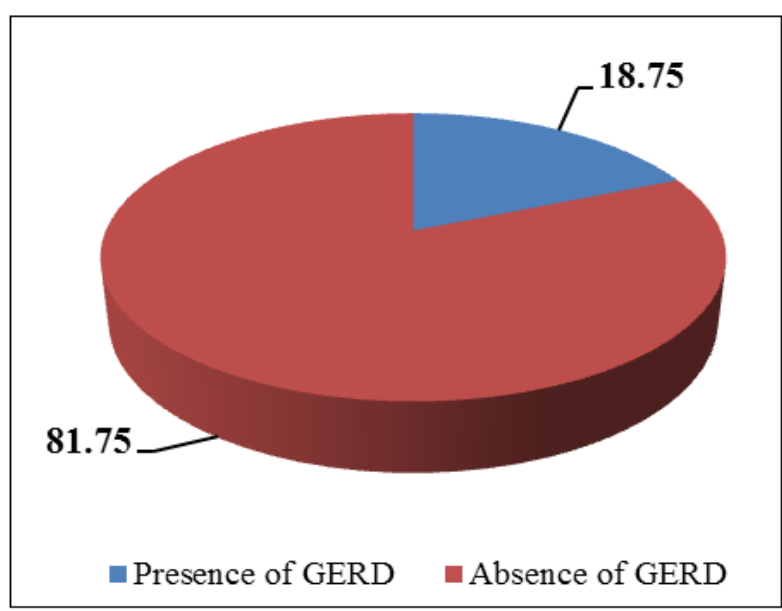

Fig-1: Showing the percentage of presence of GERD in total case)

Table-4: Showing percentage of male and female having GERD

\begin{tabular}{|l|l|l|}
\hline Gender & $\mathrm{n}=384$ & $(\%)$ \\
\hline Male & 28 & 14.89 \\
\hline Female & 44 & 22.44 \\
\hline Total & 72 & 100 \\
\hline \multicolumn{2}{|l|}{$* \mathrm{p}=0.0207$ as compared with male }
\end{tabular}

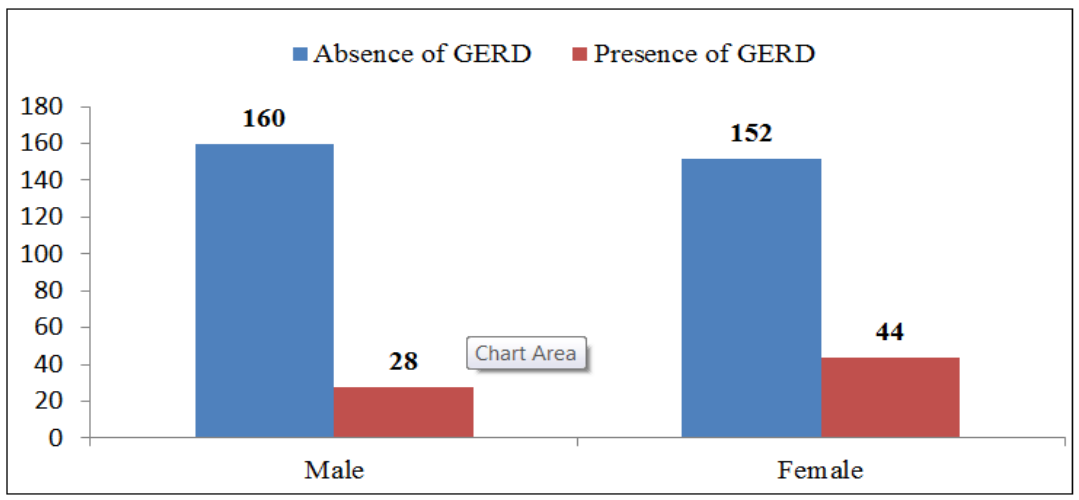

Fig-2

Table-5: Showing seventy of GERD symptoms among total GERD patient

\begin{tabular}{|l|l|l|}
\hline Mild(4-8) & Moderate(9-14) & Sever(15-18) \\
\hline 12 & 22 & 38 \\
\hline
\end{tabular}

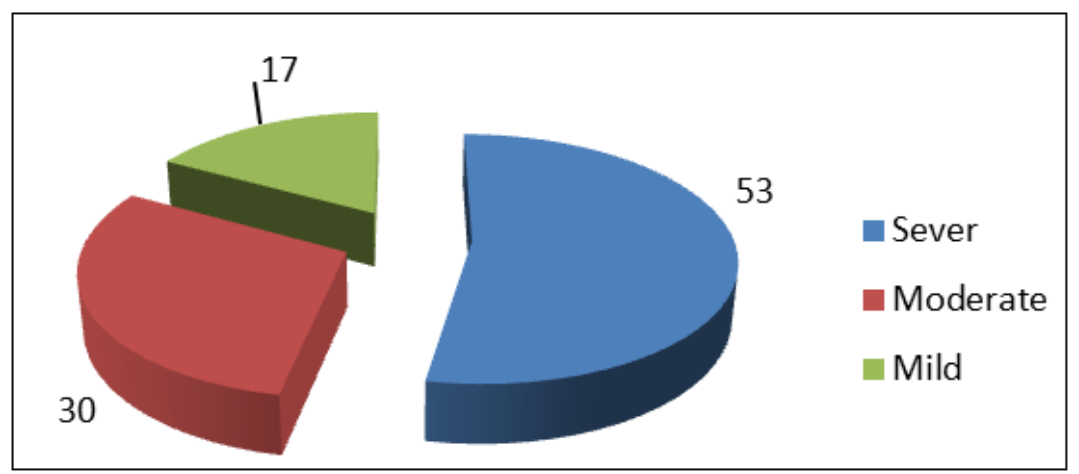

Fig-3: Showing severity of GRED symptoms 
Table-6: Showing frequency and percentage of GERD patient in different age group

\begin{tabular}{|l|l|l|l|}
\hline Age (years) & Total population & $\mathbf{n = 7 2}$ & $\mathbf{( \% )}$ \\
\hline $18-38$ & 199 & 35 & 17.50 \\
\hline $39-59$ & 130 & 27 & 20.76 \\
\hline$>59$ & 55 & 10 & 18.18 \\
\hline Total & 384 & 72 & \\
\hline \multicolumn{2}{|l|}{$\mathrm{x} 2=3,47 ; \mathrm{df}=2 ; \mathrm{p}=0.1$ which is statistically not significant }
\end{tabular}

Table-7: Showing average weight and BMI of male GERD patient and population without GERD

\begin{tabular}{|l|l|l|l|}
\hline Male Sex & Mean average weight & Mean average height & Mean BMI \\
\hline Male GERD Patient & 54.33 & 1.63 & 20.44 \\
\hline Male population without GERD & 52.66 & 1.63 & 19.82 \\
\hline
\end{tabular}

$*_{\mathrm{z}-\text { value }=16.7 ; \mathrm{p}<0.001}$

Table-8: Showing average weight and BMI of female GERD patient and population without GERD

\begin{tabular}{|l|l|l|l|}
\hline Female Sex & Mean average weight & Mean average height & Mean BMI \\
\hline Female GERD Patient & 48.66 & 1.42 & 24.13 \\
\hline Female population without GERD & 47.66 & 1.42 & 23.63 \\
\hline
\end{tabular}

$*_{\mathrm{Z}-\text { value }}=14.5 ; \mathrm{p}<0.00$

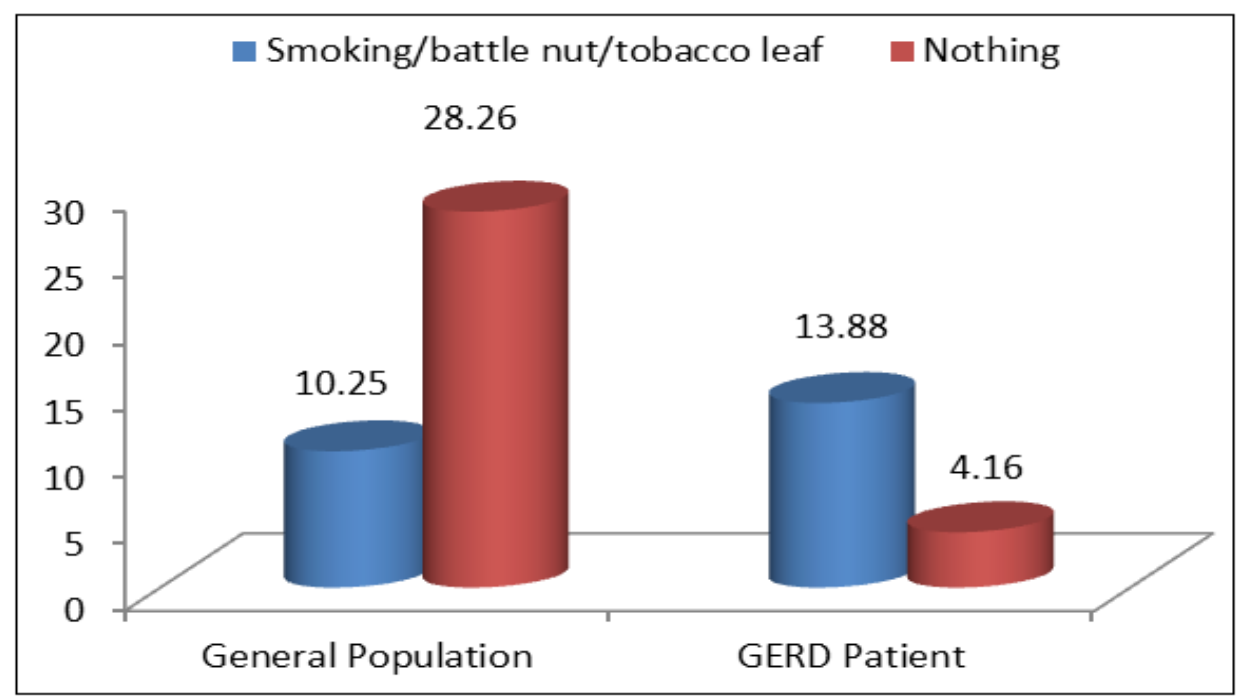

Fig-4: History of taking tobacco

\section{DiSCUSSION}

The present survey was conducted to find out the prevalence of Gastro-Esophaqecl Reflux Disease (GERD) among rural population in Bangladesh. The survey was carring, out between the periods of from 8th October, 2012 to $10^{\text {th }}$ April, 2013 in a defined population at kamaria village of sherpur district. All respondents were interviewed face to face at their home by using a structured questionnaire. Total 384 respondents were interviewed and 384 were included in the final analysis. Response rate was $100 \%$ among the respondents male and female were (188) and (196) respectively Male, female ratio was 0.96:1. Among study population $51.82 \%$ people was in age group $18-38$ years, $33.85 \%$ was in age group 39-59 years, and $14.32 \%$ was in age group $>59$ years. Our present study has shown that $18.75 \%$ people have GERD symptoms Among GERD patient 12 has mild symptoms, 22 has moderate symptoms and 38 has severe symptoms.
Praveen KS et al., shows the Prevalence of GERD in an urban adult population from northern India is $16.2 \%$ [3] Zagari RM et al., shows the prevalence $23.7 \%$ [23]. Mungan $\mathrm{Z}$ et al., studied a total of 8143 cases. Gastro esophageal reflux disease was present in $19.1 \%$ of the population [24]. Mohammed I et al., studied 1533 cases. The prevalence of gastro-esophageal reflux disease symptoms was $21 \%$ [22]. Moshkowitz $\mathrm{M}$ et al., studied 2027 subjects. Monthly GERD symptoms were reported by $21.5 \%$ [26]. Rlaz $\mathrm{H}$ et al., studied 595 students Out of which 132 (22.18\%) complained of heartburn [27]. Ter RB et al., shows Gastro esophageal reflux disease (GERD) is a common chronic condition in the United States affecting as many as $40 \%$ of aoults [25]. Gcn Chaabanc $\mathrm{N}$ et al., shows that the prevalence of frequent GERD is $24 \%$ [39]. So our study demonstrates that the prevalence of GERD is consistent with previous study though it is lower than those study which are mostly conducted in developed country. Our present study has shown that it is more common among female 
$(22.44 \%)$ than male $(14.89 \%) \quad(p=0.0207)$ which is statistically significant. In some studies shows female sex is one of the independent risk for GERD symptoms. like Hung LJ et al., showed female sex and age of 40-49 years and 50-59 years were independent risk factors related to the development of GERD [37]. llnfantlno M et al., shows Overall this study found that menopausal women were 2.9 times more likely to have GERD symptoms [41]. Fujimoto K et al., shows there is a high incidence of GERD in elderly females in Japan [37]. So it can assume from our study that female is more prone to GERD which is commonly thought. This finding of our present study is similar to most previous study. Though Ter RB et al., Studies have reported that normal males have significantly more GERD than women [28] Sorm MH et al., showed there was no difference in prevalence of any GERD symptom between two genders [36]. Cho YS et al., shows No significant difference was detected between sexes [38]. Among 72 GERD patients, 35 patients $(17.50 \%)$ are of age group 18-38 years: 27 patients $(20.76 \%)$ are of age group 3959 years; 10 patients $(18.18 \%)$ are of age group 18-38 years. But these differences of prevalence $(p=0.1)$ has no statistically significance. Hung $\mathrm{LJ}$ et al., the multivariate analysis showed that female sex and age of 40-49 years and 50-59 years were Independent risk factors related to the development of GERD [32]. Moshkowitz M et al., studied 2027 subjects. GERD symptoms were significantly more prevalent within the older age group and lower socioeconomic status [26]. Saberi-Firoozi M et al., the prevalence of GERD was higher in with a mean age of 50.25 years [40]. So our study fails to demonstrate the difference of prevalence in different age group. Average weight of GERD patient is $54.33 \mathrm{~kg}$ in case of male and $48.66 \mathrm{~kg}$ in case of female, which is greater than normal people (male$52.66 \mathrm{~kg}$, female-47.66). This difference in weight in GERD patient and general people is statistically significant. Ponce $\mathrm{J}$ et al., studied, A body mass index of $>25 \%$ was the only independent variable associated with GERD [31]. BMI of GERD patient (male-20.44, female-24.13) is greater than general population (male19.82, female-23.63). GERD patient have waist circumference male-35.66 inch, female-34.33 inch on an average which is greater than normal people (male$33 \cdot .66$, female-33.33inch). Average height of both GERD patient and general people are similar. Hajar N et al., Retrospective review of 122 adult patients. this study shows a clear association between increased reflux and higher BM (Obesity not only increases the likelihood of reflux events, as shown in previous studies, but also makes it more likely that symptoms reported during Mil-pH studies are actually due to Mil detected reflux [30]. Di Francesco V et al., studies 14 obese subjects (BMI 36-53 kg/m2), 4 men, 10 women, 27-61 years old, Gastro-esophageal reflux was significantly more frequent in obese $(57.1 \%)$ than in control group (71\%) [29]. Present study have shown that $13.88 \%$ GERD patient having history of taking tobacco leaf/battle nut/smoking, while only
$10.25 \%$ general people having similar habit. $4.16 \%$ GERD patient have no history of taking any form of tobacco, where $18.26 \%$ general people have no history of taking any form of tobacco.

Mohammed I et al., studied 1533 cases Smoking, increasing body mass index weight gain, south Asian origin and manual work were associated with gastro-esophageal reflux disease symptoms [22], Bor S et al., shows that Most GERD patients are of age group 39-58years (male-14, female-20). The prevalence of heartburn symptoms but not regurgitation, increased significantly with age [34]. The study was conducted at limited area: more data could be taken from other area. Tile sample size for our study was relatively small. The diagnosis of GERD we based on only symptoms based.

\section{CONCLUSION AND RECOMMENDATION}

The basis of the results of the present study, integrated with the understanding from the available literature, this study found that the prevalence of GERD lower than other countries especially western countries but almost similar to Asian and African countries. Present study findings show female sex, increasing weight, any form of tobacco use may be risk factor for GERD, while increasing age fail to demonstrate it. Following recommendations are laid down to reach to a rational decision: If population studied were enrolled for upper GIT endoscopy and 24 hours $\mathrm{P}^{\mathrm{h}}$ monitoring it would be possible to confirm diagnosis. As this study was done on a relatively small scale. a large-scale study needs to be conducted for further information.

Funding: No funding sources.

Conflict of interest: None declared.

Ethical approval: The study was approved by the Institutional Ethics Committee.

\section{REFERENCE}

1. Locke GR, Tally NJ, Fett SL, Zinsmister AR, Melton LJ. Prevalence and clinical spectrum of gastro esophageal reflux: a population based study in Olmsted county. Minnesota, Gastro enterology. 1997; 112: 1448-56.

2. Klauser AG. Schindlebecl NE, Muller-Lrssner P. Syrnptoms in gastro esophageal reflux disease. Lancet. 1890. 335:205-8.

3. Praveen KS, Vineet A, Kaushal M, Saurabh G, Akshay R, Mahesh PS. Prevalence, severity and risk factors of symptomatic qastro -- esophageal reflux disease among employees of a large hospital in northern india. Indian J gastroenterology. 2011; 30(3):128-134. 
4. Palmer K.R., Penman 1.0 Alimentary Tract and pancreatic disease. In: Colledge NR. Walker BR, Raison SH. editors. Davidson's Principles and Practice of Medicine 21 st ed. Edinburgh: Elsevier: 2010. p. 863-6.

5. Wong WM, Fass R. extra esophageal and atypical manifestation of GERD. J gastroenterolhe patol. 2004: 19 supple 3: s 33-s43.

6. Galmiche JP, Barthlemy P, Hamelin B. Treating the symptoms of gastro esophageal reflux disease: a double blind comparison of omeprazole and cisapride. Aliment pharmacclther. '1997; 11:765773

7. Fujiwara Y, Higuchi K, Nes.ki H. Chono S, Uno H. Kitada K. Famotidine vs. Omeprazole: a prospective randomized multicentre trial to determine efficacy in nonerosive gastro esophageal reflux disease. Aliment pharmacolther 2005; 21 supple 2:10-18.

8. Kahrilaj PJ. Gastro -esophageal reflux disease. N Engl J Med. 2008: 359: 1700-7.

9. Lajergren J, Bergstrom R, Lindgren, Nyren O. Symptomatic gastro esophageal reflux disease as risk factors for e sophaoeat adenocarcrnorna. N Engl J Med. 1999: 340:825-31.

10. Dent J, EI- Serag HB, Wallender MA, Johanson S. Epidemiology of gastro esophageal reflux disease: a systemic review: Gut. 2005; 54:710-7.

11. Kahrilaj PJ, Shi G, Manka M, Joehl RJ. Increased frequency of transient lower esophageal sphincter relaxation induced by gastric distension in reflux patient with hiatus hernia. Gastro Enterology. 2000: 118'688-95.

12. De vriesdr, van herwarden MA, Smout AJ, Samson M. Gastro esophageal pressure gradients in gastro esophageal reflux disease: relation with hiatal hernia, body mass index and esophageal acid exposure. Am J gastroenterol. 2008: 103: 1349-54.

13. Corley DA, Kubo A, Levin TR. Abdominal obesity and body mass index as risk factors for Barrett's esophaqus. Gastroenterol. 2007; 133: 34-41.

14. Goh KL. Changing epidemiology of gastroesophageal reflux disease in the ASia pacific region: an overview, $\mathbf{J}$ gastroenterolhepatol. 2004: 19:s22-5.

15. Menachem $M$, Noya $H$, Zamir H, Erwin S, Gastro-esophageal reflux disease Symptoms: prevalence, sociodemografics and treatment pattern in the adult lsraeli population. World $\mathbf{J}$ gastroenterol. 2011 March 14; 17(10)1332-33.

16. Vigneri S, Termini R, Leandro G. A comparison of five maintenance therapies for reflux esophagitis. $\mathrm{N}$ Eng $\mathrm{J}$ med. 995; 333: 1106-10.

17. Madan K, Ahuja V, Gupta SD. Impact of 24-h esophageal ph monitoring on the diagnosis of GERD, defining the gold standard. J Gastroenterol Hepatol. 2005: 20:30-7.
18. Tamanin T, Ancona C, Rodrigues-Netto N. Translation. Validation and Cross-Cultural Adaptation into Portuguese Language of the King's Health Questionnaire. Heidelberg: International Continence Society Annual Conference. 2002.

19. Brislin R, Lonner W, Thorndike R. Crosscultural research methods New York: Wiley. 1973.

20. Locke GR 3rd, Talley NJ, Fett SL, Zinsmeister AR. Melton LJ 3rd. Division of Gastroenterology and Internal Medicine. Mayo Clinic and Mayo Foundation. Rochester, Minnesota 55905, USA

21. Nilsson M, Johnsen R, Ye W, Hveem K, Lagergren J. Department of Surgery. Karolinska Hospital, SE-171 76 Stockholm, Sweden Mohammed I, Nightingale P, Trudgill NJ.

22. Mohammed I, Nightingate $P$, Trudgill NJ. Department of Gastroenrology. Sandwell General Hospital. West Bromwich B71 4HJ, UK, Aliment Pharmacol Ther. Ther 2005 Apr 1; 21(7):821-7.

23. Zagari RM, Fuccio L, Wallander MA, Johansson S, Fiocca R, Casanova S, Farahmand BY, Winchester CC, Roda E, Bazzoli F. Department of Internal Medicine and Gastroenterology, Bologna University, Policlinico Sant'Orsola. Via Massarenti n. 9. 40138 Bologna, Italy.

24. Mungan Z.Oepartment of Gastroenterohepatology, istanbul University, istanbul Medical School, istanbul, Turkey. Turk J Gastroenterol. 2012 Aug; 23(4):323-32.

25. Isolauri J, Laippala P.Department of Clinical Medicine, University of Tampere, Finland,Ann Med. 1995 Feb; 27(1) 67-70

26. Moshkowitz M, Horowitz N, Halpern Z, Santo E.Department of Gastroenterology, Tel-Aviv Sourasky Medical Center Tel-Aviv University, Tel-Aviv, Israel. World J Gastroenterol. 2011 Mar 14; 17(10): 1332-5.

27. Riaz H, Kamal SW, Aziz S.Dow Medical College. J Pak Med Assoc. 2010 Feb;60(2): 147 -50.

28. Ter RB, Johnston BT, Castell DO. Department of Medicine, Graduate Hospital. Philadelphia, PA 19146. USA. Dis Esophagus. '1998 Apr; 11(2):68.

29. Di Francesco V, Baggio E, Mastromauro M, Zoico E, Stefenelli N, Zamboni M. Panourgia MP, Frulloni L, Bovo P, Bosello O, Cavallini G. Department of Biomedical and Surgical Sciences, University of Verona, Verona, Italy. Obes Surg. 2004 Sep; 14(8): 1095-102.

30. Hajar N, Castell O, Ghomrawi H, Rackett R, Hila A. Upstate Medical University, Syracuse, NY 13210, USA. Dig Dis Sci. 2012 Jul; 57(7):1875-9.

31. Ponce J, Vegazo O, Beltran B, Jimenez J, Zapardiel J, Calle D, Pique JM, Iberge Study Group.Gastroenterolcqy Service, Hospital La Fe, 
Valencia, Spain. Aliment Pharmacol Ther, 2006 Jan $1: 23$ ( 1): 175-84,

32. Hung LJ, Hsu PI, Yang CY, Wang EM, Lai KH. Department of Family Medicine, Kaohsiung Veterans General Hospital. Kaohsiung, Taiwan. J Gastroenterol Hepatol. 2011 Jul: 26(7):1164-8.

33. Tsukanov VV, Butorin NN, Onuchina EV, Kuklin DV, Timoshenko VO, Amel'chugova OS, Rzhavicheva OS, Kasparov EV, Khomenko OV. Features of prevalence and risk factors of GERD in different age-gender groups. Eksperimental'naia i Klinicheskaia Gastroenterologiia= Experimental \& Clinical Gastroenterology. 2010 Jan 1(5):38-42.

34. Bor S, Mandiracioglu A, Kitapcioglu G. CaymazBor C, Gilbert RJ. Department of Gastroenterology, Public Health and Anesthesiology, Ege University, lzrrur. Turkey Am J Gastroenterol. 2005 Apr; 100(4):759-65.

35. Somi MH, Farhang S, Mirinezhad K, Jazayeri E, Nasseri-Moghaddam S, Moayeri S, Yasrebinia S.Liver and' Gastrointestinal Disease Research Center, Tabriz University of Medical Sciences, Tabriz, Iran. Saudi Med J. 2006 Dec: 27(12):187881.

36. Fujimoto K. Department of Internal Medicine and Gastrointestinal Endoscopy. Saga Medical School,
Nabeshima, Saga 549-8501, Japan. JP .Aliment Pharmacal Ther. 2004 Dec; 20 Suppl 8:5-8,

37. Cho YS, Choi MG, Jeong JJ, Chung WC, Lee IS. Kim SW, Han SW, Choi KY. Chung IS. Division of Gastroenterology, Department of Internal Medicine. College of Medicine, The Catholic University of Korea, Seoul, Korea, Am J Gastroenterol. 2005 Apr; 100(4):747-53.

38. Ben Chaabane N, EI Jeridi N, Ben Salem K, Hellara O, Loghmari H, Melki W. Bdiaui F, Safer L, Saltani M, Saffar H. Department of Hepatogastroenterology, CHU Monastir, Monastir, Tunisia. Jr Dis Esophagus, 2012 Jan: 25(1):4-9.

39. Saberi-Firoozi M, Khademolhosseini F, Yousefi M, Mehrabani D, Zare N, Heydari STGastroenterohepatology Research Center, Nemazee Hospital, School of Medicine.

40. Shiraz University of Medical Sciences, KarimKhan Zand Blv, Shiraz. Iran. World J Gastroenterol. 2007 Nov 7:13(41):5486-91.

41. Infantino M. Department of Nursing. CW Post/LIU. Brookville, NY. USA. J Am Acad Nurse Pract. 2008 May; 20(5):266-72. 